\title{
A laparoscopic management of Swyer syndrome in a woman with pure 46XY gonads and hypoplastic dysgenesis-a rare presentation
}

\author{
Kaavya Sathyamurthy*, Nilufer Moideen
}

Department of Obstetrics and Gynecology, Grant Government College and J. J. Group of Hospitals, Mumbai, Maharashtra, India

Received: 08 December 2021

Accepted: 05 January 2022

\section{*Correspondence:}

Dr. Kaavya Sathyamurthy,

E-mail: kaavyasathyamurthy@gmail.com

Copyright: (c) the author(s), publisher and licensee Medip Academy. This is an open-access article distributed under the terms of the Creative Commons Attribution Non-Commercial License, which permits unrestricted non-commercial use, distribution, and reproduction in any medium, provided the original work is properly cited.

\begin{abstract}
Swyer syndrome is also known as complete/pure gonadal dysgenesis and is associated with an absence of testicular differentiation in a phenotypic female with a 46, XY karyotype. A 23-year-old married girl had come with complaints of primary infertility. She was averagely built and nourished. She had well developed secondary sexual characteristics like breast development, axillary hairs, and pubic hairs (Tanner's stage 4) secondary to receiving HRT for getting menses. External genitalia were of female type. Karyotype showed genotype of 46, XY. Magnetic resonance imaging revealed hypoplastic uterus with rudimentary fallopian tubes, and fibrotic gonad like tissue. A diagnosis of Swyer syndrome was made. The patient was started on hormonal replacement therapy. Dysgenetic streak gonads were removed laparoscopically. Pathologic examination revealed seminiferous tubules, rete testis and epididymis without evidence of malignant transformation. The patient tolerated the procedure well. Thus, laparoscopic prophylactic gonadectomy revealed to be an economical, straightforward and simple procedure in this patient and risk of neoplasia could be prevented.
\end{abstract}

Keywords: Gonadal dysgenesis, Primary amenorrhea, Swyer syndrome

\section{INTRODUCTION}

Disorders of sex development (DSD) are congenital anomalies characterized by atypical chromosomal, gonadal, or anatomical sex development. ${ }^{1}$ Complete gonadal dysgenesis also known as pure gonadal dysgenesis have features such as a female phenotype, nonambiguous genitalia, the presence of Müllerian derivatives, gonadal dysgenesis, and a normal karyotype. ${ }^{2}$ Swyer's syndrome, is a rare cause of DSD with an incidence of 1:100,000. Swyer's syndrome belongs to category of rare diseases and was discovered by Dr. Swyer. ${ }^{3}$ Dr. Swyer described two women whom had a 46, XY karyotype, primary amenorrhea, female external genitalia, normal vagina and cervix in $1955 .{ }^{4}$ There is incomplete masculinization in view of lack in the production of testosterone and Müllerian-inhibiting factors causing development of dysgenetic or streak gonadal tissue..$^{5}$ Molecular and genetic abnormalities associated with this condition include mutations in multiple genes, most commonly the SRY gene in Swyer syndrome patients. $^{6}$

In Swyer syndrome patients may have either small or undeveloped breasts, but normal axillary and pubic hair. The external genitalia is that of a females, the upper part of the vagina and tubes are normal or are hypoplastic, and the uterus is usually rudimentary or maybe normal in some cases. ${ }^{7}$ The gonads are dysgenetic strips composed of only fibrous tissue; they do not exhibit any hormonal function, gametogenesis. $^{8}$ The patients karyotype is $46, \mathrm{XY}$, but they do not have well defined ovaries or testes. ${ }^{8}$ These dysgenetic gonads have a high possibility for development of gonadoblastomas and/or dysgerminomas. ${ }^{8}$ Streak gonads are usually removed surgically because there is an increased risk of developing a gonadal tumor. ${ }^{9}$ Genetic counselling is recommended for affected individuals and their families. ${ }^{10}$ 


\section{CASE REPORT}

A 23-year-old female presented to our out-patient department with complaints of primary infertility. On detailed history, she revealed she never attained menarche (primary amenorrhoea). She was married for 3 years and had normal sexual life. The couple had no coital difficulty. There was no history of cyclical abdominal pain or urinary retention. No h/o drugs intake, chemoradiation. She did not have excessive facial hair growth, galactorrhoea or any central nervous symptoms such as headache or visual disturbances. There was no past significant surgical or medical history. She has two other female siblings (45 and 36 years) both of them attained their menarche at the appropriate age, regularly menstruating and have children.

On general examination, her height was $157 \mathrm{~cm}$, weight $65.9 \mathrm{~kg}$ with a BMI of $26.7 \mathrm{~kg} / \mathrm{m}^{2}$. Waist circumference 86 $\mathrm{cm}$ and head circumference of $97 \mathrm{~cm}$. There were no multiple naevi, wide carrying angle, webbing of neck or any other Turner stigmata. There was acanthosis nigricans present. No hirsutism. There was no skeletal abnormalities or midline defects. Systemic examination did not reveal any cardiac/other abnormalities. Examination of secondary sexual characteristics revealed well developed breasts (tanner stage 4). Axillary hair and pubic hairs tanner stage 4 .

Examination of the external genitalia was of female type (Figure 1) labia majora and minora were normal with no clitoromegaly (Figure 1). No mass palpable along labia majora or inguinal canal. Vaginal orifice was normal in length and well oestrogenised. On per speculum examination, hypoplastic cervix seen at summit of vagina, the same confirmed on a per vaginal examination (Figure 2). Uterus was felt on per vaginal and per rectal examination, but was hypoplastic. After thorough investigations, her hormone profile was as follows-

Table 1: Lab investigations.

\begin{tabular}{|ll|}
\hline Hormones & Values \\
\hline Sr. FSH & $11.4 \mathrm{mIU} / \mathrm{ml}$ \\
\hline Sr. LH & $15.2 \mathrm{mIU} / \mathrm{ml}$ \\
\hline Sr. TSH & $1.56 \mathrm{mcIU} / \mathrm{ml}$ \\
\hline Sr. PRL & $15.9 \mathrm{ng} / \mathrm{ml}$ \\
\hline T. testosterone & $0.6 \mathrm{ng} / \mathrm{ml}$ \\
\hline Sr. Estradiol & $10 \mathrm{pg} / \mathrm{ml}$ \\
\hline
\end{tabular}

Ultrasound of abdomen and pelvis showed a rudimentary uterus with ovaries not visualised and magnetic resonance imaging (3 Tesla MRI) revealed hypoplastic uterus $3.7 \times 2.9 \times 1.7 \mathrm{~cm}$ with no clear delineation of upper and lower uterine segment. No evidence of any ovotestes in pelvis. Vaginal vault was un-remarkable and both the kidneys were normal. There was evidence of fibrotic tissue at the deep inguinal ring bilaterally with gonadal vessels reaching up to it, likely representing dysplastic fibrotic bands. Karyotype by G-banding was done which showed a genotype of 46, XY (Figure 3).
Couple was thoroughly counselled and she was further subjected to diagnostic laparoscopy and the findings demonstrated a hypoplastic uterus with normally present fallopian tubes (Figure 4). Ovaries could not be visualized; fibrous tissue were seen at the level of deep inguinal ring which was assumed to be streak gonads. Rest of inguinal canal was seen on both sides which was blind with a fibrotic band connecting to the gonads (Figure 5). No other pelvic abnormalities were seen. Taking into consideration the genotype of XY, removal of these fibrotic structures was done bilaterally and was sent for histopathology (Figure 6). The report showed streak gonads having all structures of testes i.e., vas deferens, rete testes, seminiferous tubules, epididymis and no evidence of atypia or malignancy (Figure 7). Counselling of couple was done. She was started on hormonal replacement therapy (HRT) with conjugated estrogen for 3 months and is suggested supplementation with medroxyprogesterone acetate cyclically after she menstruates.

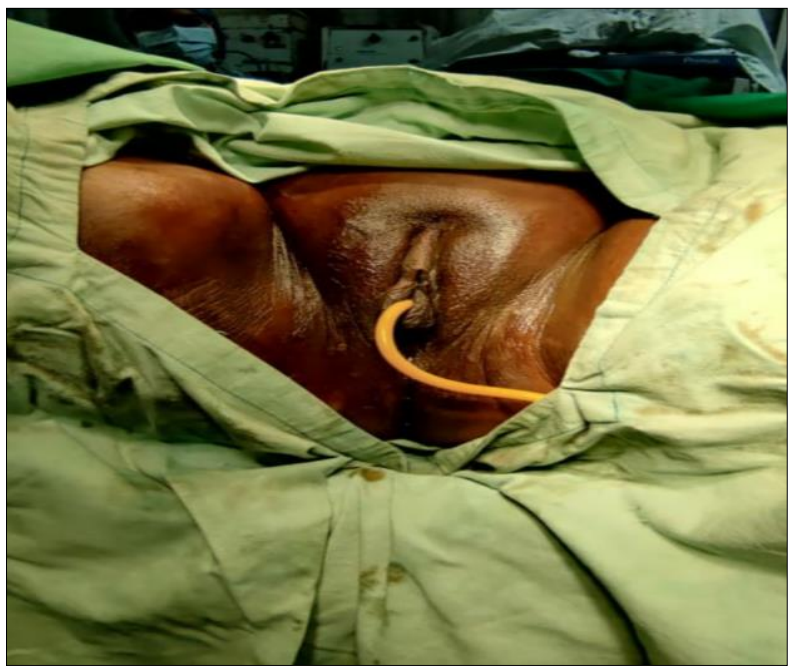

Figure 1: Well-formed female external genitalia.

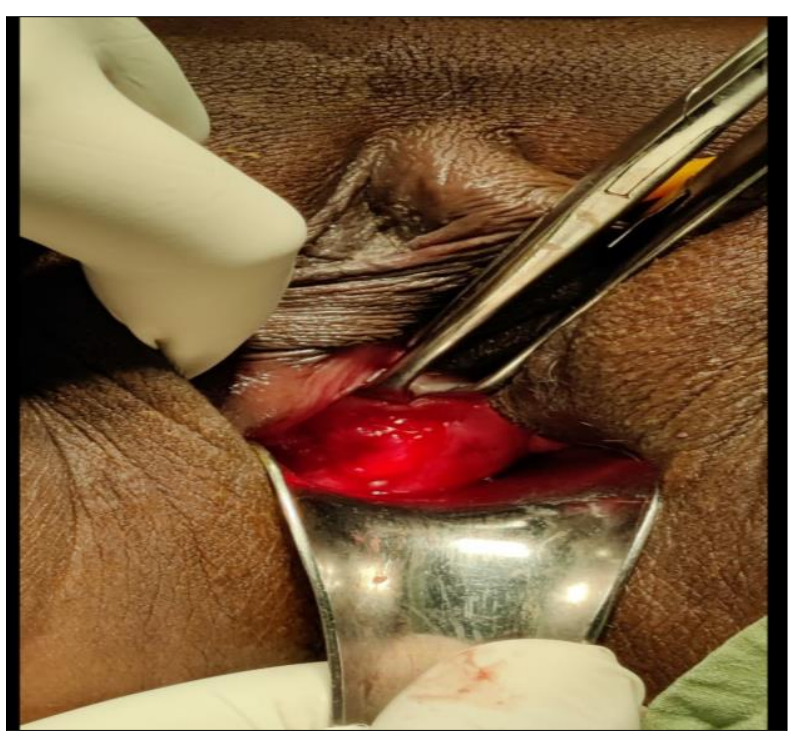

Figure 2: Hypoplastic cervix. 


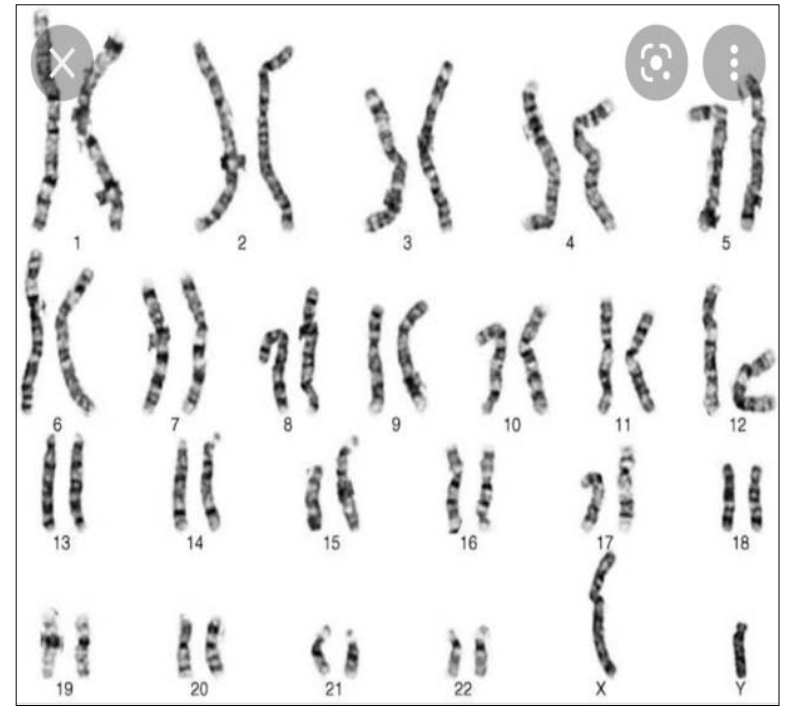

Figure 3: Karyotype showing 46XY.

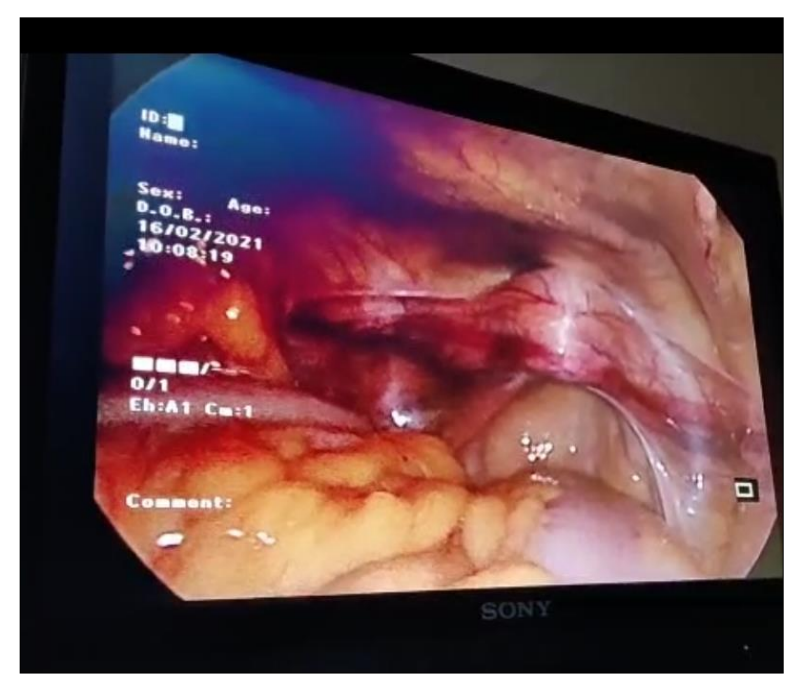

Figure 4: Hypoplastic uterus.

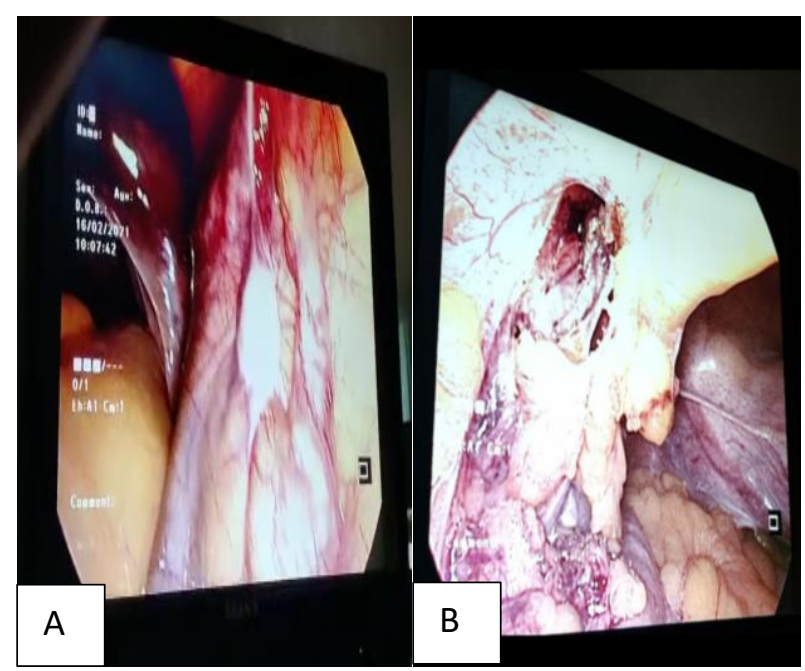

Figure 5 (A and B): Dysgenetic gonad and fibrotic bands.

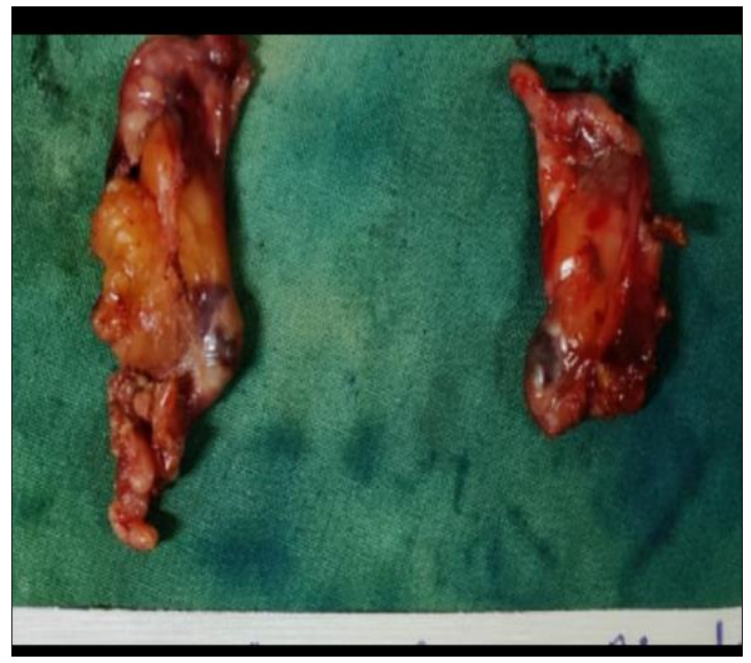

Figure 6: Streak gonads after gonadectomy.
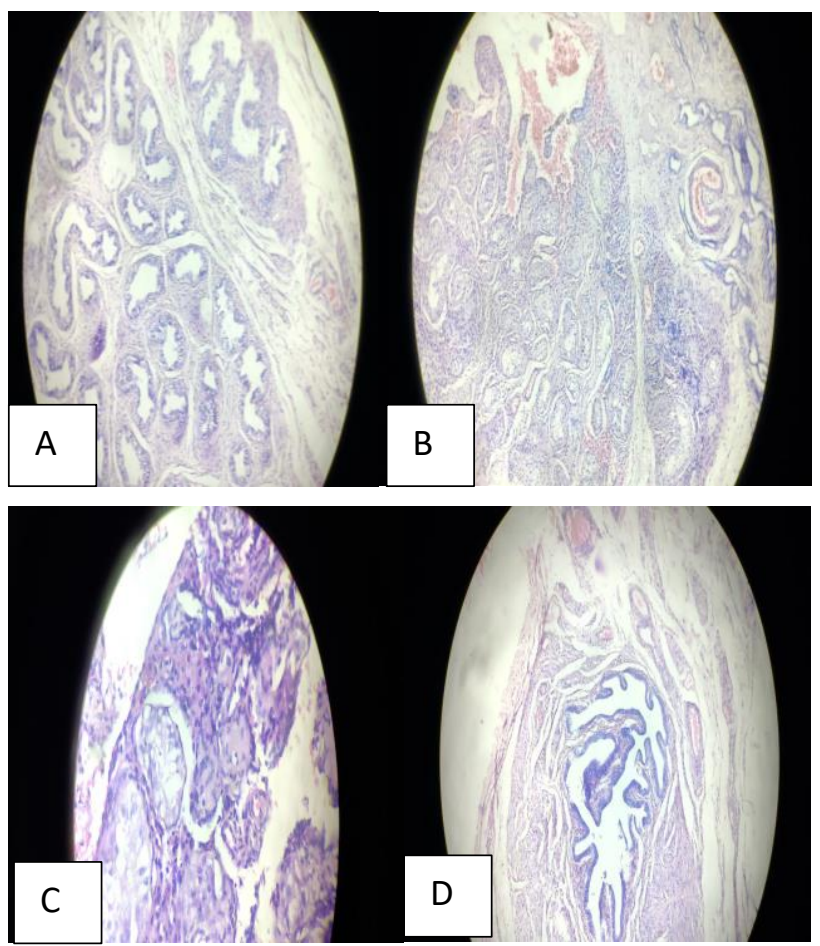

Figure 7 (A-D): Histopathology images (From left to right)-Seminiferous tubules, vas deferens, Sertoli with Leydig cells and Fallopian tube.

\section{DISCUSSION}

Swyer syndrome also known as pure/complete gonadal dysgenesis, is a DSD. ${ }^{3}$ In a XY fetus, the sexual differentiation is based on the development of testes. ${ }^{11}$ The SRY, the sex-determining region of the $Y$ chromosome is an important gene which helps in testicular formation in the $2^{\text {nd }}$ month of fetal growth. ${ }^{11}$ Four mutations of SRY account for many cases of Swyer syndrome. ${ }^{12}$ The mutation of other genes in the sex differentiation pathway such as the autosomal genes DHH, MAP3K1, NR5A1, SOX9, WT1, and DAX1 on the X 
chromosome can also lead to pure gonadal dysgenesis. ${ }^{12}$ Swyer syndrome may be inherited or might result because of denovo mutation. It may be either autosomal dominant, autosomal recessive, $\mathrm{X}$ linked or $\mathrm{Y}$ linked. ${ }^{13}$ The bipotential gonads fail to differentiate into testes in an XY fetus due to a mutation and lose their gametogenic function. ${ }^{14}$ These mutations maybe inherited or newly developed. ${ }^{13}$ Our patient had no family history of such mutation. As a result, no testosterone or anti-Mullerian hormone $(\mathrm{AMH})$ is produced. The patient will be a female phenotypically as there is no virilization. Also, the Mullerian ducts develop into uterus, fallopian tube, cervix, and vagina.

Our patient had typical female external genitalia. The uterus and fallopian tubes formed in our patient were hypoplastic as seen in MRI, but the gonads (ovaries or testes) are not functional; affected individuals have undeveloped clumps, fibrotic tissue called streak or dysgenetic gonads. The residual gonadal tissue often becomes cancerous, so it is usually removed surgically early in life. Adrenal gland is not affected; hence production of androgens is not affected and most of these persons develop pubic hair. There is some breast development. In our case breast development and pubic hair were tanner stage 4 due to exogenously given hormones. The patient in our case was a normal-statured women with primary amenorrhea with clinical features of sexual infantilism whose genotype was pure XY and streak gonads.

People with Swyer syndrome are typically raised as girls and have an identity of a female, as in our case. ${ }^{12}$ As ovaries are not functional, patients with Swyer syndrome are usually given HRT during adolescence to induce menstruation and development of female secondary sex characteristics such as breast enlargement and uterine growth. ${ }^{12}$ These patients can have a normal sexual intercourse and they need HRT for development of breast and to prevent osteoporosis. ${ }^{15}$ They can conceive using donor oocytes and artificial reproductive techniques or in case of hypoplastic uterus surrogacy can be tried. ${ }^{12,16}$

Our patient had only impaired sexual development hence it was a case of isolated Swyer syndrome. Gonadoblastomas are seen in $20-30 \%$ of women with Swyer syndrome. ${ }^{17}$ The main differential diagnosis of Swyer syndrome is mixed gonadal dysgenesis which is more frequently seen than the former. ${ }^{18}$ Gonadectomy was done. In our case, the gonads on histopathology showed testicular differentiation and no ovarian differentiation. The genotype in our case was 46XY. There was no evidence of malignancy. After gonadectomy includes, patients are usually treated with estrogen till development of secondary sexual characters. ${ }^{12}$ Error! Bookmark not defined.Later combination of estrogen and progesterone long-term therapy is usually given. Our patient was given conjugated estrogen initially for 3 months which would stimulate secondary sexual characters and endometrial mucosal thickening, followed by combination therapy of conjugated estrogen and medroxyprogesterone acetate cyclically. Patient was also given calcium supplements to prevent osteoporosis. Early diagnosis of Swyer's syndrome is pivotal as there is high risk of dysgerminoma that can develop at an early age.

\section{CONCLUSION}

Swyer's syndrome belongs to rare disorders which causes primary amenorrhea. Detailed testing is essential in the diagnosis of Swyer's syndrome. Early diagnosis is very determining as there is risk of gonadal malignancy in young age group. Treatment includes removal of the streak gonads, early institution of HRT for induction of puberty, improving bone mineral density, and also counselling regarding fertility options.

Funding: No funding sources Conflict of interest: None declared

Ethical approval: Not required

\section{REFERENCES}

1. Mendonca BB, Domenice S, Arnhold IJ, Costa EM. 46, XY disorders of sex development (DSD). Clin Endocrinol. 2009;70(2):173-87.

2. Pun R, Pudasaini S, Mahaseth R, Shrestha K. Dysgerminoma in Pseudohermaphroditism: A Case Report. Nepalese Med J. 2020;3(2):384-7.

3. Kulathilake DT, Jayasundara C. A germ cell tumor in a patient with Swyer syndrome with ambiguous genitalia. BMC Res Notes. 2015;8(1):1-5.

4. Michala L, Goswami D, Creighton SM, Conway GS. Swyer syndrome: presentation and outcomes. Int $\mathbf{J}$ Obstetr Gynaecol. 2008;115(6):737-41.

5. Pieniak K, Olszewska A, Grymowicz M, Smolarczyk R. Swyer Syndrome-Gonadectomy Performed 17 Years after Diagnosis: Case Report. J Med Genetics. 1992;29(8):539-41.

6. Kellermayer R, Halvax L, Czakó M, Shahid M, Dhillon VS, Husain SA et al. A novel frame shift mutation in the HMG box of the SRY gene in a patient with complete 46, XY pure gonadal dysgenesis. Diagnostic Molecular Pathol. 2005;14(3):159-63.

7. Khare J, Deb P, Srivastava P, Reddy BH. Swyer syndrome: The gender swayer? Alexandria J Med. 2017;53(2):197-200.

8. Afsana F, Pathan MF, Shelly SJ. A Rare Case of Swyer Syndrome. BIRDEM Med J. 2019;9(2):174-6.

9. Da Silva Rios S, Monteiro IC, Braz Dos Santos LG, Caldas NG, Chen AC, Chen JR et al. A case of Swyer syndrome associated with advanced gonadal dysgerminoma involving long survival. Case Rep Oncol. 2015;8(1):179-84.

10. King TF, Conway GS. Swyer syndrome. Curr Opinion Endocrinol Diabetes Obesity. 2014;21(6):504-10.

11. Rey RA, Grinspon RP. Normal male sexual differentiation and aetiology of disorders of sex 
development. Best Practice Res Clin Endocrinol Metab. 2011;25(2):221-38.

12. Priya PK, Mishra VV, Choudhary S, Rizvi JS. A case of primary amenorrhea with Swyer syndrome. J Human Reproduct Sci. 2017;10(4):310.

13. Gupta A, Bajaj R, Jindal UN. A rare case of swyer syndrome in two sisters with successful pregnancy outcome in both. J Human Reproductive Sci. 2019;12(3):267.

14. Nef S, Parada LF. Hormones in male sexual development. Genes Development. 2000;14(24):3075-86.

15. Michala L, Goswami D, Creighton SM, Conway GS. Swyer syndrome: presentation and outcomes. Int $\mathrm{J}$ Obstetr Gynaecol. 2008;115(6):737-41.
16. Tulic I, Tulic L, Micic J. Pregnancy in patient with Swyer syndrome. Fertility and sterility. 2011;95(5):1789-e1.

17. Wilson EE, Vuitch F, Carr BR. Laparoscopic removal of dysgenetic gonads containing a gonadoblastoma in a patient with Swyer syndrome. Obstetr gynecol. 1992;79(5Pt 2):842-4.

18. Elagwany AS, Eltawab S, Abouzaid ZS. 46, XY complete gonadal dysgenesis (Swyer syndrome): Report of two different cases. Apollo Med. 2016;13(1):63-6.

Cite this article as: Sathyamurthy K, Moideen N. A laparoscopic management of Swyer syndrome in a woman with pure 46XY gonads and hypoplastic dysgenesis-a rare presentation. Int J Reprod Contracept Obstet Gynecol 2022;11:620-4. 